\title{
Telephone-based cognitive behavioral therapy for depression in Parkinson disease
}

\section{A randomized controlled trial}

Roseanne D. Dobkin, PhD, Sarah L. Mann, PhD, Michael A. Gara, PhD, Alejandro Interian, PhD, Kailyn M. Rodriguez, BA, and Matthew Menza, MD

Neurology ${ }^{\circledR}$ 2020;94:e1764-1773. doi:10.1212/WNL.0000000000009292

\section{Abstract}

\section{Objective}

To determine whether, for patients with depression and Parkinson disease (PD), telephonebased cognitive-behavioral treatment (T-CBT) alleviates depressive symptoms significantly more than treatment as usual (TAU), we conducted a randomized controlled trial to evaluate the efficacy of a 10-session T-CBT intervention for depression in PD, compared to TAU.

\section{Methods}

Seventy-two people with PD (PWP) were randomized to T-CBT + TAU or TAU only. T-CBT tailored to PWPs' unique needs was provided weekly for 3 months, then monthly during 6-month follow-up. CBT targeted negative thoughts (e.g., "I have no control"; "I am helpless") and behaviors (e.g., social withdrawal, excessive worry). It also trained care partners to help PWP practice healthy habits. Blind raters assessed outcomes at baseline, midtreatment, treatment end, and 1 and 6 months post-treatment. Analyses were intent to treat.

\section{Results}

T-CBT outperformed TAU on all depression, anxiety, and quality of life measures. The primary outcome (Hamilton Depression Rating Scale score) improved significantly in T-CBT compared to TAU by treatment end. Mean improvement from baseline was 6.53 points for T-CBT and -0.27 points for TAU $(p<0.0001)$; gains persisted over 6-month follow-up $(p<0.0001)$. Improvements were moderated by a reduction in negative thoughts in the T-CBT group only, reflecting treatment target engagement.

\section{Conclusions}

T-CBT may be an effective depression intervention that addresses a significant unmet PD treatment need and bypasses access barriers to multidisciplinary, evidence-based care.

\section{Clinicaltrials.gov identifier}

NCT02505737.

\section{Classification of evidence}

This study provides Class I evidence that for patients with depression and PD, T-CBT significantly alleviated depressive symptoms compared to usual care.

\author{
Correspondence \\ Dr. Dobkin \\ dobkinro@rutgers.edu
}

\section{RELATED ARTICLE}

\section{Editorial}

A call for better depression treatment in people with Parkinson disease

Page 691

\section{MORE ONLINE}

$\rightarrow$ Class of Evidence

Criteria for rating

therapeutic and diagnostic studies

NPub.org/coe 


\section{Glossary}

ARR = absolute risk reduction; BDI $=$ Beck Depression Inventory; CBT = cognitive-behavioral therapy; CGI-I = Clinical Global Impression Improvement Scale; CI = confidence interval; dPD = depression in Parkinson disease; DSM-5 = Diagnostic and Statistical Manual of Mental Disorders, 5th edition; HAM-A = Hamilton Anxiety Rating Scale; HAM-D = Hamilton Depression Rating Scale; $\mathbf{M C S}=$ mental health composite score; $\mathbf{M D D}=$ major depressive disorder; $\mathbf{N N T}=$ number needed to treat; PWP = people with Parkinson disease; PD = Parkinson disease; RCT = randomized controlled trial; SF-36 = Short Form-36; T-CBT $=$ telephone-based cognitive-behavioral therapy; TAU $=$ treatment as usual.

Depression affects up to $50 \%$ of patients with Parkinson disease (PD) ${ }^{1}$ with widespread implications for PD management. Depression in PD (dPD) is associated with faster physical and cognitive decline, ${ }^{2}$ earlier initiation of dopaminergic replacement, ${ }^{3}$ medication nonadherence, ${ }^{4}$ greater prospective fall risk, ${ }^{5}$ and increased heath service utilization ${ }^{6}$ and costs. ${ }^{7}$ It predicts disability and distress over PD's defining motor symptoms, ${ }^{8}$ and surpasses disease severity as the strongest PD quality of life predictor. ${ }^{9}$ Optimal dPD management can restore patients' nondepressed functional baseline, ${ }^{10}$ yet spontaneous remission is rare. ${ }^{11}$

Contributing to its consequences, $\mathrm{dPD}$ is overlooked in over $60 \%$ of patients with significant symptoms ${ }^{12}$ and often undertreated. Though antidepressants typically constitute firstline intervention, data regarding efficacy, tolerability, and patient acceptability are mixed. ${ }^{13}$ This unmet treatment need complicates PD outcomes, ${ }^{14}$ underscoring the need for innovative care models to enhance treatment engagement.

Cognitive-behavioral therapy (CBT), a personalized, coping skills-based treatment approach, ${ }^{15}$ has shown promising results for dPD in pilots ${ }^{16,17}$ and 1 randomized controlled trial $(\mathrm{RCT}) .{ }^{18}$ Although patients may prefer nonpharmacologic depression treatments, ${ }^{19}$ access to PD-informed psychotherapy is limited by physical, geographic, and workforce barriers. ${ }^{20}$ Teleneurology is bypassing such obstacles to specialty medical care, ${ }^{21}$ as the need for patient-centered, interdisciplinary PD management is recognized. ${ }^{22}$ Telemedicine shows similar potential to facilitate personalized, neuropsychiatric dPD care, ${ }^{16}$ but there is no controlled research to this effect.

This RCT evaluated the efficacy of specialized, telephonebased CBT for depression in PD, compared to communitybased treatment as usual (TAU). Acute and longer-term treatment effects, as well as moderators of treatment response, were examined.

\section{Methods}

\section{Design}

This RCT, conducted at an academic medical center, enrolled 72 people with PD (PWP) and their care partners. This study utilized an additive design to compare outcomes for an intervention group, who received telephone-based CBT (T-CBT) plus usual care, with those of an existing-practice control group, who received usual care only. This design was selected to measure T-CBT-augmented PD care against the current standard of care for this population. PWP and their care partners were randomly assigned (as dyads) to either $\mathrm{T}-\mathrm{CBT}+\mathrm{TAU}$ or TAU after eligibility requirements were confirmed, following the baseline evaluation. Randomization was stratified by baseline antidepressant medication use, such that individuals taking antidepressants were equally represented in both groups.

Allocations were determined in the order in which supervision (by R.D.D.) and scoring of each baseline assessment was completed. M.A.G. assigned participants to groups using multiple-password-protected randomization software to which he retained sole access. Allocation was stratified by antidepressant medication status only and blind to all other baseline data, such that M.A.G. did not have access to any information that could identify or in any way characterize the participant he was randomizing. See figure 1 .

Figure 1 Consolidated Standards of Reporting Trials (CONSORT) diagram

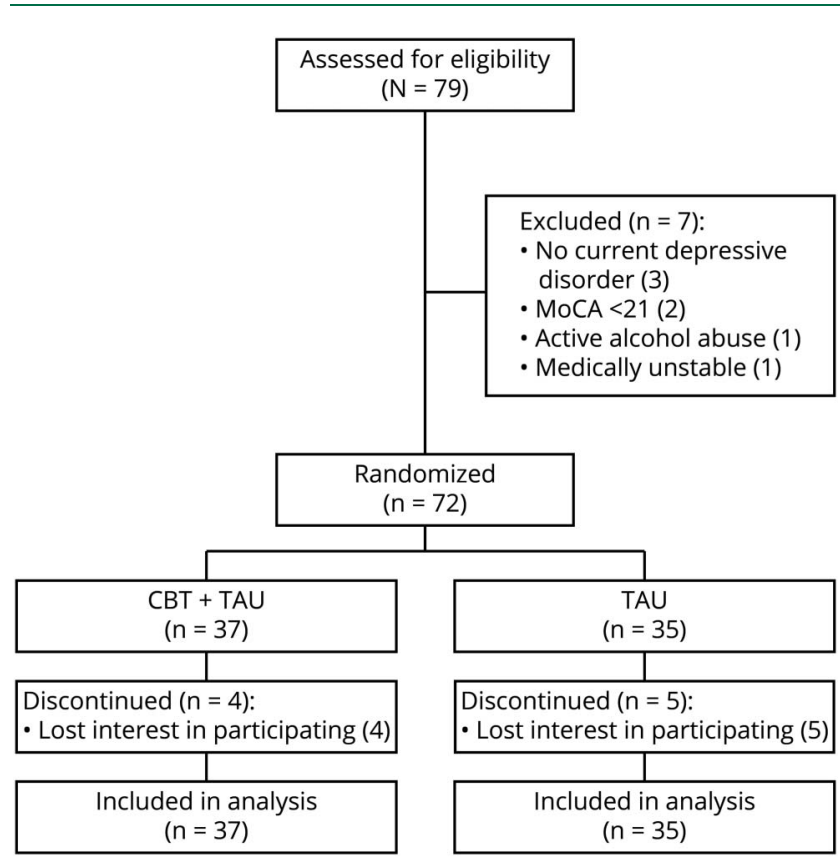

Flow diagram of study participation. CBT = cognitive-behavioral therapy; MoCA = Montreal Cognitive Assessment; TAU = treatment as usual. 
T-CBT was provided weekly for 10 one-hour sessions, then monthly if desired, during 6-month follow-up (16 sessions maximum). T-CBT targeted negative thoughts (e.g., "I have no control"; "I am helpless") and behaviors (e.g., avoidance, excessive worry, lack of exercise), and trained care partners by telephone to help PWP practice healthy habits between sessions. TAU measures were defined by participants' health care teams and included psychiatric consultations, medication management, supportive psychotherapy, and all aspects of routine PD care. Condition-blind raters assessed outcomes at baseline, acute treatment midpoint, acute treatment end, and 1 and 6 months post-treatment. The 6-month follow-up evaluation occurred approximately 9 months after enrollment. No travel was required of participants, as all study procedures were conducted remotely. Individuals received $\$ 50$ for each completed evaluation.

\section{Standard protocol approvals, registrations, and patient consents}

The Rutgers-Robert Wood Johnson Medical School institutional review board approved the study. Written informed consent was obtained from all participants before initiating study procedures. The study is registered at ClinicalTrials.gov (NCT02505737).

\section{Participants}

Participants were recruited from August 2015 through September 2017 from the Departments of Neurology and Psychiatry at Rutgers-Robert Wood Johnson Medical School, local PD support groups, and Fox Trial Finder (a clinical trial match tool). Follow-up ended when the last evaluation was completed in June 2018.

Prospective participants with PD and depressive symptoms called the study team in response to advertisements, flyers, and referrals by their treating neurologist or psychiatrist. Inclusion criteria were (1) PD by National Institute of Neurological Disorders and Stroke research criteria ${ }^{23}$; (2) DSM-5 $5^{24}$ depressive disorder diagnosis per Structured Clinical Interview for DSM Disorders ${ }^{25}$; (3) age 35-85 years; (4) stable PD and mental health treatment $\geq 6$ weeks (movement disorder drugs, antidepressants, other psychotropics, and community-based psychotherapy); and (5) family member or friend willing to participate. National Institute of Mental Health guidelines regarding dPD diagnosis were followed. ${ }^{26}$ Exclusion criteria were (1) possible dementia or marked cognitive impairment (Montreal Cognitive Assessment score $<21^{27}$ ); (2) active suicidal plans or intent by first author's assessment (R.D.D.); (3) unstable serious medical conditions (e.g., cancer); or (4) primary psychotic, bipolar, or substance abuse disorder per DSM-5 criteria. $^{24}$

\section{Measures}

Change in Hamilton Depression Rating Scale (HAM-D) ${ }^{28}$ score was the primary outcome. Secondary outcomes included responder status (defined a priori as depression very much improved or much improved on the Clinical Global
Impression Improvement Scale [CGI-I], score $\leq 2){ }^{29}$ depression severity (Beck Depression Inventory [BDI]), ${ }^{15}$ anxiety (Hamilton Anxiety Rating Scale [HAM-A]), ${ }^{30}$ and quality of life (Medical Outcomes Study Short Form-36 [SF$36]^{31}$ mental health composite score $\left.[\mathrm{MCS}]\right)$. In addition to mood and energy levels, the MCS reflects the extent to which health interferes with daily functioning (e.g., socializing, chores) and captures cognitions about general health and wellness associated with proactive self-care. ${ }^{32}$ Negative thinking, a key intervention target, was assessed with the Inference Questionnaire. ${ }^{33}$ The CGI-I assessment protocol required clear evidence of adaptive functional consequences of mood improvements to score $\leq 2$ (treatment response). All measures and scoring criteria were prespecified.

\section{Interventions}

\section{Study conditions}

Control: enhanced treatment as usual

TAU was defined as routine medical and psychiatric treatment from participants' medical and mental health providers (e.g., neurologists, psychiatrists, therapists), without the study team's input. TAU was enhanced via clinical monitoring by study staff and provision of a resource list including major PD foundations and national and local mental health resources. As described in the Results, TAU for the majority of participants (in both study conditions) included taking antidepressant medication or receiving psychotherapy in the community from any provider of their choosing. All control participants had the opportunity to receive the $\mathrm{PD}$-informed T-CBT intervention after completion of the 6-month followup evaluation. Study staff did not interact with care partners in TAU, apart from incidental telephone contact for administrative purposes, such as ensuring return of mailed self-report surveys and payment vouchers.

\section{Intervention: T-CBT + enhanced TAU}

The CBT group received the study intervention and TAU. Treatment was guided by the Chronic Care Model $^{34}$ to enhance PD self-management. In this systematic, patientcentered approach to chronic illness management, patients proactively collaborate with their providers to problem-solve about illness-related challenges and enhance their quality of life through self-care. The manual-guided CBT intervention was tailored to the needs of the $\mathrm{dPD}$ population, with modules focusing on behavioral activation, cognitive restructuring, anxiety management, and sleep hygiene (manual available on request). The manual, which was also designed for future implementation in direct patient care settings as well as clinical trials, also served as a participant workbook to supplement treatment. Within the manualized domains, emphases were personalized to individuals' symptom presentations and preferences. Care partners received telephone-based coaching in how to support and encourage PWPs' use of new CBT coping skills between therapy sessions. Of note, care partner coaching was intended to supplement T-CBT for the PWP; it was not a targeted intervention for caregiver distress. Treatment was 
provided by Masters-level therapists supervised by R.D.D. Participants received a 10-chapter CBT for dPD workbook (available on request) to supplement treatment.

In addition to coping skills to ameliorate depression, T-CBT emphasized strategies for optimizing PD care (e.g., exercise, medication adherence, facilitating referrals and followthrough for ancillary therapies). Primary intervention targets included PD-specific concerns (e.g., fear of falling, reactions to "on"-"off" fluctuations, levodopa phobia), and thoughts blocking PD self-management (e.g., "I have no control"; "I am helpless"). Treatment was personalized to improve adaptive responding to individuals' most pressing concerns, with the goals of improving mood- and healthrelated outcomes.

\section{Statistical analyses}

Data were analyzed with SAS 9.0 using an intent-to-treat approach. Linear mixed models analyses were used to examine treatment effects on the dependent variables of interest. Each model included 1 between-group variable (T-CBT vs TAU), 1 repeated-measure variable (time), and a group-bytime interaction (effect of interest). We considered several covariance structures between repeated measures and determined the best structure (variance components) using the Akaike Information Criterion.

For each dependent variable, we analyzed the group-by-time effect of interest separately at each post-randomization assessment point, only when the omnibus test was significant at $p<0.01$, to control for number of comparisons. Fisher exact test was used to compare T-CBT and TAU treatment response rates.

To test whether the treatment target reduction in negative thoughts moderated treatment effects (CBT vs TAU) on HAM-D scores, we used PROCESS, ${ }^{35}$ a computational tool for conducting path-analysis-based moderation and mediation analyses, either alone or in combination, with bootstrap estimates of confidence intervals (CIs). The PROCESS macro can be implemented in both SAS and SPSS. Changes in HAM-D and Inference Questionnaire scores, respectively, were operationalized as end-of-treatment scores, partialing out enrollment scores.

\section{Power}

Sample size was determined a priori using power analyses, which assumed 58 PWP and care partners completing the study (20\% attrition rate). Observed SDs were taken from baseline control data in our prior RCT of CBT for dPD. ${ }^{18}$ The study was powered to test post-treatment group differences in HAM-D (primary outcome). Controlling for baseline scores and demographic covariates, we considered 20 scenarios: within-group SDs ranged 4-5 and within-group correlation, baseline to endpoint, ranged 0.55-0.70. At $p=0.05$, median power was 0.80 . We previously observed a group difference of $7.30,{ }^{18}$ which yielded power $>0.99$ in all 20 scenarios.

\section{Primary research questions and level of evidence}

The primary research question was whether a 10-session course of specialized T-CBT for dPD would lead to greater reductions in depressive symptoms than community-based TAU. Secondary questions assessed the effect of T-CBT on associated psychiatric and functional outcomes such as anxiety and quality of life, the durability of treatment effects, and moderators of treatment response. The study was single-blind (assessors were blind to treatment condition) and randomized-controlled, with no baseline differences between treatment groups. Primary outcomes and inclusion/ exclusion criteria were clearly defined a priori. The statistician (M.A.G.) had sole access to the randomization scheme and was blind to all study data, except baseline antidepressant status, for stratification purposes. A retention rate over $80 \%$ was observed throughout the 9-month trial. Results provide Class I evidence that T-CBT for dPD significantly surpassed usual care in providing marked, durable improvements in depression, anxiety, and quality of life.

\section{Data availability}

On publication, the following will be made available to researchers whose proposed use of the data for a specified purpose has been approved by R.D.D.: deidentified participant data, data dictionary, study protocol, informed consent form, and statistical analysis plan. These materials are available from R.D.D. (dobkinro@rutgers.edu) by request, with a signed data access agreement.

\section{Results}

Seventy-two PWP and their care partners were randomized: 37 to CBT (51\%) and 35 (49\%) to TAU. Sixty-three PWP (88\%) completed the study. Most $(\mathrm{n}=63[88 \%])$ met major depressive disorder (MDD) criteria; among those individuals, $39(62 \%)$ reported recurrent episodes. As part of usual care, 64 PWP (89\%) were taking levodopa, 50 PWP (70\%) were taking antidepressants, and 10 PWP (14\%) continued receiving psychotherapy from community providers of their choice throughout the trial. Forty-three PWP (60\%) reported prior psychotherapy. The groups' baseline clinical and demographic factors did not differ (table 1).

\section{Treatment effects}

\section{Primary outcome}

T-CBT was associated with significant improvements in mood (HAM-D) compared to TAU over the course of the trial $\left(F_{4,249}=14.89, p<0.0001\right)$ (tables 2 and 3 and figure 2$)$. Effects at the end of treatment $(p<0.0001)$ were maintained at 6-month follow-up $(p<0.0001)$. Post-treatment, T-CBT participants' HAM-D mean score was 14.44 (95\% CI, 12.97-15.93); TAU mean score was 21.33 (95\% CI, 19.76-22.89). Mean improvement from baseline was 6.53 points for T-CBT (95\% CI, 5.07-7.99) and -0.27 points for TAU (95\% CI, -1.81 to 1.27 , Cohen $d=1.69$ ). At 6-month follow-up, T-CBT participants' HAM-D mean was 15.37 
Table 1 Baseline demographic and clinical information

\begin{tabular}{|c|c|c|c|c|}
\hline & Total $(n=72)$ & CBT $(n=37)$ & $\operatorname{TAU}(n=35)$ & $p$ Value \\
\hline Sex & & & & NS \\
\hline Male & $35(48.61)$ & $17(23.61)$ & $18(25.00)$ & \\
\hline Female & $37(51.39)$ & $20(27.78)$ & $17(23.61)$ & \\
\hline Age, y & $65.22 \pm 9.63$ & $65.62 \pm 9.76$ & $64.80 \pm 9.62$ & NS \\
\hline Age at PD onset, y & $59.49 \pm 11.08$ & $59.62 \pm 11.57)$ & $59.34 \pm 10.70$ & NS \\
\hline Education, y & & & & NS \\
\hline High school diploma/some college & $23(31.94)$ & $11(15.28)$ & $12(16.66)$ & \\
\hline College degree & $26(36.11)$ & $14(19.44)$ & $12(16.67)$ & \\
\hline Graduate degree & $23(31.95)$ & $12(16.67)$ & $11(15.28)$ & \\
\hline PD duration, y & $6.33 \pm 6.34$ & $6.95 \pm 7.82$ & $5.65 \pm 4.20$ & NS \\
\hline Depression duration, y & $2.87 \pm 1.03$ & $3.10 \pm 1.15$ & $2.62 \pm 0.83$ & NS \\
\hline New onset PD & $12(16.67)$ & $5(6.94)$ & $7(9.72)$ & NS \\
\hline No. of current psychiatric diagnoses & & & & NS \\
\hline 1 & $38(52.78)$ & $18(25.00)$ & $20(27.78)$ & \\
\hline 2 & $26(36.11)$ & $14(19.44)$ & $12(16.67)$ & \\
\hline 3 & $7(9.72)$ & $4(5.56)$ & $3(4.17)$ & \\
\hline 4 & $1(1.39)$ & $1(1.39)$ & $0(0)$ & \\
\hline Comorbid anxiety disorder & $25(34.72)$ & $14(19.44)$ & $11(15.28)$ & NS \\
\hline Current levodopa use & $64(88.89)$ & $33(45.83)$ & $31(43.06)$ & NS \\
\hline Current antidepressant use & $50(69.44)$ & $25(34.72)$ & $25(34.72)$ & NS \\
\hline Past psychotherapy & $43(59.72)$ & $22(30.56)$ & $21(29.17)$ & NS \\
\hline Current psychotherapy & $10(13.89)$ & $4(5.56)$ & $6(8.33)$ & NS \\
\hline No. of comorbid medical conditions & $3.14 \pm 2.27$ & $3.17 \pm 1.98$ & $3.11 \pm 2.56$ & NS \\
\hline Deep brain stimulation & $3(4.17)$ & $2(2.78)$ & 1 (1.39) & NS \\
\hline MoCA & $26.07 \pm 2.45$ & $26.19 \pm 2.62$ & $25.94 \pm 2.27$ & NS \\
\hline HAM-D & $21.01 \pm 3.48^{\mathrm{a}}$ & $20.97 \pm 4.40^{\mathrm{b}}$ & $21.06 \pm 4.40^{b}$ & NS \\
\hline BDI & $20.94 \pm 7.51^{a}$ & $21.00 \pm 7.82)^{b}$ & $20.89 \pm 7.81^{b}$ & NS \\
\hline HAM-A & $19.88 \pm 3.66^{\mathrm{a}}$ & $20.19 \pm 4.25^{\mathrm{b}}$ & $19.54 \pm 4.25^{\mathrm{b}}$ & NS \\
\hline CGI depression severity & & & & NS \\
\hline 3: Mild & $2(2.78)$ & $1(1.39)$ & $1(1.39)$ & \\
\hline 4: Moderate & $42(58.33)$ & $23(31.94)$ & $19(26.39)$ & \\
\hline 5: Marked & $28(38.89)$ & $13(18.06)$ & $15(20.83)$ & \\
\hline Quality of life & $35.34 \pm 10.06^{a}$ & $34.06 \pm 11.27^{b}$ & $36.36 \pm 10.99^{b}$ & NS \\
\hline
\end{tabular}

Abbreviations: BDI = Beck Depression Inventory; CGI = Clinical Global Impression Severity Scale; HAM-A = Hamilton Anxiety Rating Scale; HAM-D = Hamilton Depression Rating Scale; MoCA = Montreal Cognitive Assessment; PD = Parkinson disease.

Quality of life indicated by the mental health composite score of the Medical Outcomes Survey Short Form-36.

Categorical data presented as $n(\%)$, continuous data as mean \pm SD.

a Observed means \pm SDs are presented for baseline outcome measures for the full sample.

${ }^{\mathrm{b}}$ Least square means \pm SDs (from linear mixed models) are presented for baseline scores within each treatment group (cognitive-behavioral therapy [CBT] and treatment as usual [TAU]) for consistency with table 2. 
Table 2 Acute outcomes: baseline to end of treatment

\begin{tabular}{|c|c|c|c|c|c|c|c|}
\hline \multirow[b]{2}{*}{ Measure } & \multicolumn{2}{|c|}{ CBT, $\operatorname{mean}^{\mathrm{a}}$ (SD) } & \multicolumn{2}{|c|}{ TAU, $\operatorname{mean}^{\mathrm{a}}(\mathrm{SD})$} & \multicolumn{2}{|c|}{ Mean improvement ${ }^{\mathrm{b}}(95 \% \mathrm{Cl})$} & \multirow{2}{*}{$\begin{array}{l}\text { Difference }{ }^{c} \\
(95 \% \mathrm{CI}), \text { CBT vs TAU }\end{array}$} \\
\hline & Baseline & Endpoint & Baseline & Endpoint & CBT & TAU & \\
\hline HAM-D ${ }^{d}$ & $20.97(4.40)$ & $14.44(4.55)$ & $21.06(4.40)$ & $21.33(4.66)$ & $6.53(5.07-7.99)$ & $-0.27(-1.81$ to 1.27$)$ & $6.88(4.73-9.03)$ \\
\hline$B D I^{d}$ & $21.00(7.82)$ & $13.09(8.14)$ & $20.89(7.81)$ & $19.03(8.37)$ & $7.91(5.23-10.59)$ & $1.85(-0.98$ to 4.68$)$ & $5.94(2.08-9.80)$ \\
\hline HAM-A ${ }^{d}$ & $20.19(4.25)$ & $16.48(4.39)$ & $19.54(4.25)$ & $19.88(4.25)$ & $3.71(2.33-5.10)$ & $-0.34(-1.80$ to 1.12$)$ & $3.41(1.33-5.48)$ \\
\hline Quality of life $e^{e}$ & $34.06(11.27)$ & $42.54(11.38)$ & $36.36(10.99)$ & $38.06(11.61)$ & $8.48(5.52-11.44)$ & $1.70(-1.41$ to 4.80$)$ & $4.48(-0.86$ to 9.83$)$ \\
\hline
\end{tabular}

Abbreviations: $\mathrm{BDI}=$ Beck Depression Inventory; $\mathrm{CBT}=$ cognitive-behavioral therapy; $\mathrm{Cl}$ = confidence interval; HAM-A = Hamilton Anxiety Rating Scale; HAM-D = Hamilton Depression Rating Scale; TAU = treatment as usual.

Quality of life indicated by the mental health composite score of the Medical Outcomes Survey Short Form-36.

a Least square means from linear mixed models are presented.

b Within-group least square mean change over time.

Differential rates of change between treatment groups over time.

${ }^{\mathrm{d}}$ Score decrease $=$ improvement.

e Score increase $=$ improvement.

(95\% CI, 13.87-16.86); TAU mean was 20.53 (95\% CI, 18.96-22.09). Mean improvement from baseline for T-CBT was 5.60 (95\% CI, 4.12-7.07) and for TAU was 0.53 (95\% CI, -1.01 to 2.07$)$.

\section{Secondary outcomes}

Treatment response rates

T-CBT had significantly more treatment responders (CGI-I $\leq$ $2)$ than TAU $(p<0.0001)$. At end of treatment, 15 T-CBT participants $(41 \%)$ vs 0 in TAU met response criteria (number needed to treat $[\mathrm{NNT}], 2.4$ [95\% CI, 1.7-3.9]; absolute risk reduction $[\mathrm{ARR}], 0.42[95 \% \mathrm{CI}, 0.25-0.58])$. At 6-month follow-up, 14 T-CBT participants (38\%) vs 0 in TAU met response criteria (NNT, 2.6 [95\% CI, 1.8-4.4]; ARR, 0.39 [95\% CI, 0.23-0.55]) (figure 3). Of note, treatment responders showed mild to minimal symptomatology on the HAM-D (mean, 9.67; 95\% CI, 7.86-11.48) and BDI (7.14; 95\% CI, 4.63-9.65) at treatment endpoint and 6-month follow-up (HAM-D: mean, 11.21; 95\% CI, 9.09-13.34; BDI: mean, 8.71; 95\% CI, 5.14-12.28), reflecting clinically significant symptom change.

\section{Psychiatric and functional measures}

All secondary outcomes favored T-CBT, including selfreported depressive symptoms $(\mathrm{BDI})\left(F_{4,244}=5.07, p<\right.$ $0.001)$, anxiety (HAM-A) $\left(F_{4,249}=8.63, p<0.0001\right)$, and quality of life (SF-36 MCS) $\left(F_{4,241}=3.62, p=0.007\right)$. Effects were evident after acute treatment and maintained through 6-month follow-up (tables 2 and 3).

BDI mean scores at treatment's end were 13.09 (95\% CI, 10.44-15.74) for T-CBT and 19.03 (95\% CI, 16.23-21.84) for TAU. Mean improvement from BDI baseline was 7.91 (95\% CI, 5.23-10.59) for T-CBT and 1.85 (95\% CI, -0.98 to 4.68) for TAU (Cohen $d=0.88$ ). At 6-month follow-up, mean BDI scores were 13.93 (95\% CI, 11.25-16.59) for T-CBT and 18.49 (95\% CI, 15.72-21.27) for TAU. Mean improvement from baseline was 7.07 (95\% CI, 4.38-9.77) for T-CBT and 2.39 ( $95 \%$ CI, -0.41 to 5.20 ) for TAU. Anxiety and quality of life showed similar patterns (table 2).

\section{Target engagement}

Using PROCESS ${ }^{35}$ as described above to test whether reduction in negative thoughts moderated T-CBT effects (vs

Table 3 Longer-term outcomes: baseline to 6-month follow-up (9 months postbaseline)

\begin{tabular}{|c|c|c|c|c|c|c|c|}
\hline \multirow[b]{2}{*}{ Measure } & \multicolumn{2}{|c|}{ CBT, mean ${ }^{a}$ (SD) } & \multicolumn{2}{|c|}{ TAU, mean ${ }^{a}$ (SD) } & \multicolumn{2}{|c|}{ Mean improvement ${ }^{\mathrm{b}}(95 \% \mathrm{Cl})$} & \multirow{2}{*}{$\begin{array}{l}\text { CBT vs TAU, } \\
\text { difference }^{\text {c }}(95 \% \mathrm{Cl})\end{array}$} \\
\hline & Baseline & 6-Month & Baseline & 6-Month & CBT & TAU & \\
\hline HAM-D ${ }^{d}$ & $20.97(4.40)$ & $15.37(4.59)$ & $21.06(4.40)$ & $20.53(4.66)$ & $5.60(4.12-7.07)$ & $0.53(-1.01$ to 2.07$)$ & $5.15(2.99-7.31)$ \\
\hline $\mathrm{BDI}^{\mathrm{d}}$ & $21.00(7.82)$ & $13.93(8.21)$ & $20.89(7.81)$ & $18.49(8.29)$ & $7.07(4.38-9.77)$ & $2.39(-0.41$ to 5.20$)$ & $4.57(0.71-8.42)$ \\
\hline HAM-A ${ }^{d}$ & $20.19(4.25)$ & $16.51(4.43)$ & $19.54(4.25)$ & $18.91(4.50)$ & $3.68(2.28-5.07)$ & 0.63 (-0.83 to 2.09$)$ & $2.40(0.32-4.49)$ \\
\hline Quality of life $\mathrm{e}^{\mathrm{e}}$ & $34.06(11.27)$ & $41.37(11.49)$ & $36.36(10.99)$ & $36.66(11.48)$ & $7.30(4.08-10.53)$ & $0.30(-2.98$ to 3.58$)$ & $4.70(-0.64$ to 10.04$)$ \\
\hline
\end{tabular}

Abbreviations: $\mathrm{BDI}=$ Beck Depression Inventory; $\mathrm{CBT}=$ cognitive-behavioral therapy; $\mathrm{Cl}$ = confidence interval; HAM-A = Hamilton Anxiety Rating Scale; HAM-D = Hamilton Depression Rating Scale; TAU = treatment as usual.

Quality of life indicated by the mental health composite score of the Medical Outcomes Survey Short Form-36.

a Least square means from linear mixed models are presented.

${ }^{b}$ Within-group least square mean change over time.

'Differential rates of change between treatment groups over time.

${ }^{\mathrm{d}}$ Score increase $=$ improvement.

e Score decrease $=$ improvement. 
Figure 2 Magnitude of Hamilton Depression Rating Scale (HAM-D) score change over time by study condition

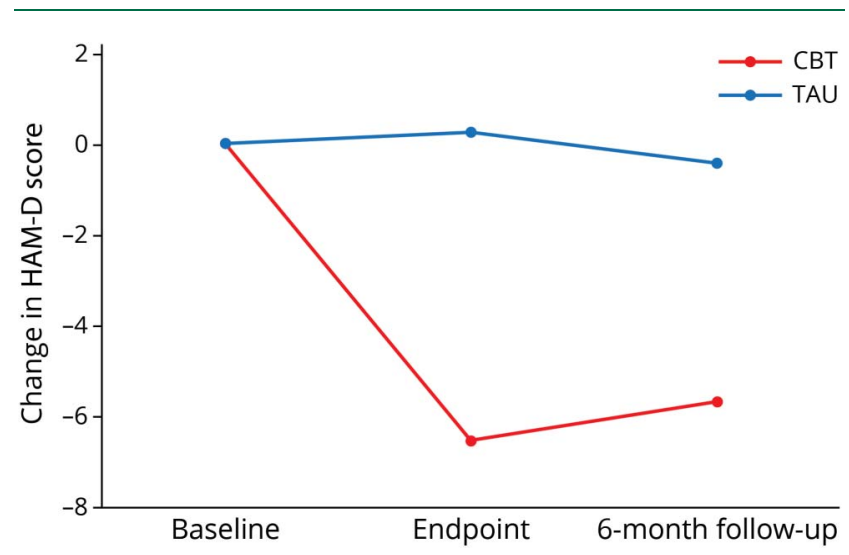

Participants in telephone-based cognitive-behavioral therapy (CBT) showed a marked, durable decrease in clinician-rated depression symptoms (HAMD) over the course of the trial, compared to treatment as usual (TAU) participants' persistent depressive symptomatology.

TAU) on depressive symptoms (HAM-D), we found $R^{2}=$ $0.55, F_{3,68}=27.5, p<0.0001$, for the moderation model. The interaction of change in negative thoughts with treatment group (T-CBT vs TAU) yielded a significant $R^{2}$ increase of $9 \%, F_{1,68}=14.0, p=0.0004$. T-CBT had its most potent ameliorative effects on depression when negative thoughts showed the most pronounced decline, whereas its effects were attenuated when negative thoughts persisted.

\section{Discussion}

$\mathrm{dPD}$ is common and often undertreated, with broad, deleterious consequences for disease management. To address this unmet need, much remains to be learned about effective dPD interventions and strategies for leveraging access to specialty mental health care. In the first RCT of a telemedicine intervention for dPD, a 3-month course of dPD-informed T-CBT was associated with significant symptom reduction compared to TAU at the end of treatment on clinicianadministered (HAM-D) and self-report (BDI) depression measures. In T-CBT, 15 participants (41\%) met a stringent, a priori treatment-response threshold of depression "much improved" (CGI-I $\leq 2$ ) at treatment's end, reflecting a marked impact of symptom reduction on daily functioning. The NNT was 2.4 with an ARR of $42 \%$. All acute gains were maintained over 6-month follow-up. In TAU, by contrast, no participants met response criteria, and group mean depression scores were unchanged from baseline.

The use of an existing practice control group highlights the substantial, incremental mood improvements gained by adding the T-CBT intervention to current $\mathrm{dPD}$ care (TAU) over the outcomes of TAU alone. ${ }^{36}$ Secondary outcomes likewise favored T-CBT, reflecting significant improvements in anxiety and quality of life. Moderation analyses demonstrated target engagement of negative thoughts, as T-CBT exerted its strongest effects on depression when negative thoughts showed the most marked decline. The intervention was feasible and highly acceptable, yielding an $88 \%$ retention rate over the 9-month trial.

The large effect sizes of T-CBT on clinician-rated $(d=1.69)$ and self-reported $(d=0.88)$ measures of depression were comparable to those observed in the only prior RCT of CBT for dPD (HAM-D: $d=1.59$; BDI: $d=1.10$ ), which examined face-to-face treatment. ${ }^{18}$ The current results reflect comparable effectiveness of telephone-based treatment, a modality with the potential to surmount obstacles limiting specialized depression care in the PD population. These effect sizes approach the upper bound of those in RCTs of CBT for depression in chronic neurologic disorders $(d=0.39-2.07)^{37}$ and exceed the upper bound in many RCTs of CBT for depression in older

Figure 3 Clinical Global Impression Improvement Scale (CGI-I) distributions at end of treatment and 6-month follow-up
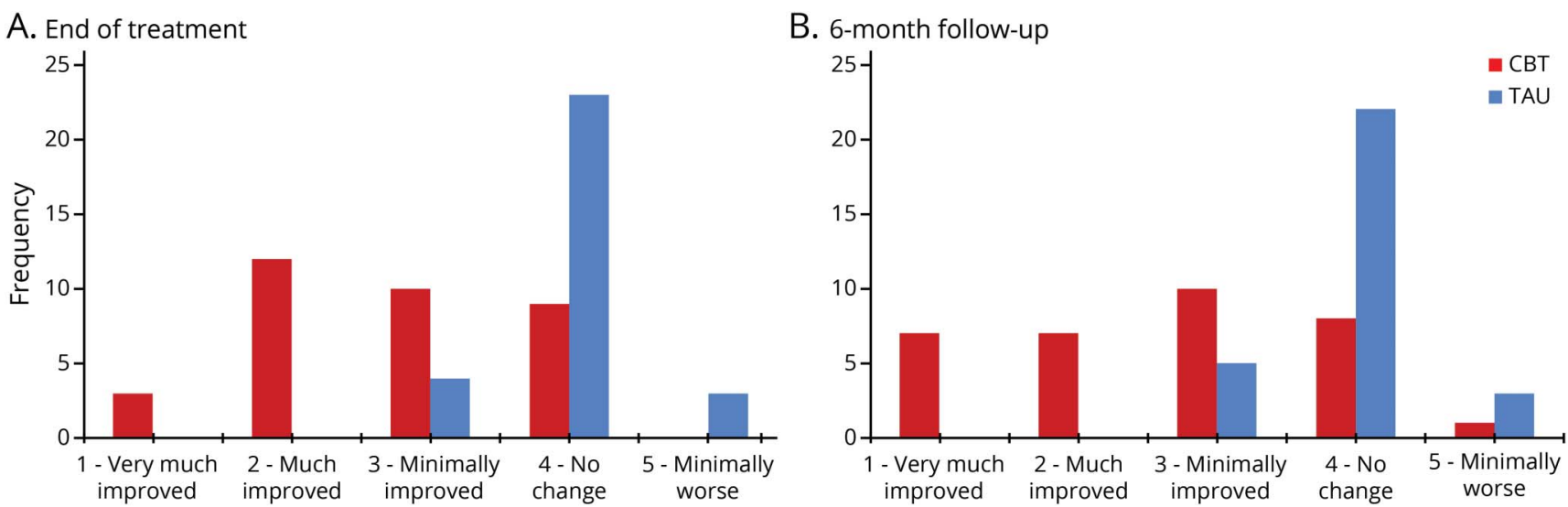

CGI-I score distributions at end of treatment ( $\mathrm{A} ; 3$ months postbaseline) and 6-month follow-up ( $\mathrm{B}$; 9 months postbaseline) reflect the clinical significance and durability of telephone-based cognitive-behavioral therapy (CBT) treatment gains over treatment as usual (TAU). 
adults $(d=0.70-1.34)^{38}$ and in a recent, large $(\mathrm{n}=469)$, multisite RCT of CBT added to pharmacotherapy for treatment-resistant depression $(d=0.53-0.77) .{ }^{39}$ These findings are notable in this sample characterized by multiple treatment-refractory factors including high anxiety, medical comorbidities, chronic pain, insomnia, depression chronicity (current episode mean 2.87 years), relapses ( $n=39,62 \%$ of those with MDD), and limited prior treatment response. ${ }^{40}$

As $\mathrm{PD}$ progresses, illness management requires proactive selfcare, to which depression poses major challenges ${ }^{41}$ : following a precise medication regimen, initiating and engaging in therapies (e.g., speech, physical therapy), and exercising regularly, while responding to unpredictable symptom fluctuations. The current results suggest that telephone-delivered CBT can beneficially augment standard neurologic care by addressing the specific psychosocial consequences of depression that thwart these complex PD management demands. PD-informed T-CBT targets the negative, healthrelated cognitions that interfere with daily activities and impede adaptive coping with PD challenges, as well as the avoidant behaviors that typify $\mathrm{dPD}^{42}$ and maintain negative mood. ${ }^{43}$ The T-CBT-related functional improvements observed in this trial reflect the potential for effective $\mathrm{dPD}$ treatment to help PWP engage with their care team to optimize PD self-management. Improved routine self-care, in turn, empowers PWP to choose adaptive means of coping with daily symptom fluctuations and acute health challenges, ${ }^{44}$ reducing barriers to the meaningful activities that support positive mood.

Several limitations bear on the interpretation of these findings. For one, these results may not generalize to individuals with more advanced PD and dementia.

Second, an existing-practice control condition (TAU) was utilized in order to compare intervention outcomes to the current standard of care. While this design has been described as "indispensable in randomized effectiveness trials that evaluate whether new interventions can replace or augment existing practices, ${ }^{36}$ and provides direct policy guidance on the additive value of T-CBT to current practice, TAU may also enhance effect sizes relative to other types of comparison conditions.

Third, it is not possible to fully disaggregate the effects of this T-CBT intervention from nonspecific factors (e.g., therapeutic relationship, time, attention) that likely contribute to all psychotherapy outcomes. ${ }^{45}$ This is important to highlight as T-CBT provided, on average, more contact with mental health providers than TAU did. Routine PD care does not incorporate a standardized psychotherapy intervention (telemedicine or in-person), and TAU was broadly comparable between study conditions. However, the marked, durable decline in depressive symptoms in the T-CBT group only-and the relationship of this pattern of change to reduction in negative thoughts, reflecting successful target engagement-significantly reduce the likelihood that results are solely attributable to nonspecific factors like clinician attention. Moreover, spontaneous remission of dPD is rare. ${ }^{11}$ $\mathrm{PD}$ is a chronic stressor, and disease progression tends to exacerbate psychosocial and neurobiological contributions to depressive symptomatology. ${ }^{46}$

Fourth, this protocol included an a priori test of T-CBT's effectiveness at reducing negative thoughts, a key treatment target, but it was not designed to assess the relative contributions of specific components of the intervention (e.g., cognitive, behavioral, and caregiver engagement strategies) or other clinical factors (e.g., antidepressant medication status) to the overall treatment effect, which will be the focus of future dismantling studies. Though the small number of participants not taking antidepressant medications $(\mathrm{n}=22[30 \%])$ also precludes meaningful exploratory analyses of the effect of $\mathrm{ADM}$ on $\mathrm{T}$-CBT response in the current study, evidence from prior work (with a more balanced sample with respect to $\mathrm{ADM}$ use) reflected greater benefits of antidepressants for somatic symptoms of dPD only, in the context of combined treatment. ${ }^{47}$ In addition, prior research has shown that caregiver involvement in dPD treatment enhances patient response, ${ }^{48}$ indicating a need for further investigation into the nature and magnitude of this effect.

Fifth, while $41 \%$ of T-CBT participants met or surpassed the stringent criteria of depression "much improved" (CGI-I $\leq 2)$, and mean HAM-D scores decreased more than 1.5 SDs in the T-CBT group, this arm in aggregate reported moderate residual symptoms post-treatment (HAM-D, mean 14.45). Though in clear contrast to the more severe symptoms persisting in TAU (HAM-D, mean 21.33), this finding is likely attributable to the resemblance between some symptoms of PD and depression (e.g., fatigue, psychomotor slowing) and the use of strict inclusive scoring protocols. ${ }^{26}$ On the BDI, which emphasizes cognitive over somatic symptoms, CBT participants selfreported mild, subthreshold symptomatology post-treatment (mean 13.09). Overall, these findings parallel our prior RCT of $\mathrm{CBT}$ for $\mathrm{dPD}$, in which targeted cognitive and behavioral symptoms improved more than somatic symptoms. ${ }^{47}$

Finally, while remote delivery of interdisciplinary PD services is growing and increasingly recognized as critical for advancing care, limitations remain on insurance coverage for telemental health services like T-CBT. At this time, 36 states and Washington, $\mathrm{DC}$, require private insurers to provide coverage parity for in-person and telemedicine-delivered care, while 21 states and Washington, DC, have such policies in Medicaid, ${ }^{49}$ with the availability of specific telemental health services subject to states' scope-of-practice laws. Reimbursement also remains subject to state-specific limitations on the telehealth eligibility of patients and originating sites. However, it is increasingly common for mental health providers to offer telemental health services on a sliding-scale, fee-for-service basis. In addition, all major PD foundations are engaged in grassroots and legislative efforts to improve access to telemedicine by increasing coverage, including federal reimbursement. ${ }^{50}$ 
This RCT provides Class I evidence that specialized T-CBT significantly improves depression, anxiety, and quality of life in PD compared to usual care; that these treatment effects are durable; and that improvements in depression are moderated by the reduction of negative thoughts, reflecting target engagement. T-CBT may be an effective depression intervention that can bypass access barriers to multidisciplinary, evidencebased PD care in order to address a significant unmet treatment need. While preliminary, these findings support the promise of telemedicine to expand the reach of evidence-based, PDinformed depression treatment, and its substantial benefits for PD self-management, into routine neurologic care. Findings also address 2 generalizability questions central to the goal of extending access to $\mathrm{dPD}$ care. That is, individuals need not live near specialized mental health services or be able to travel to weekly therapy appointments to benefit from these PDinformed interventions.

Innovations in telemedicine that are expanding access to interdisciplinary, evidence-based services now stand ready to improve quality of care - and quality of life - for many more PWP and their families. To that end, further research is necessary to understand the potential contributions of specialized telemental health to PD management, and to support policy changes that facilitate optimal, patient-centered PD care. As depression is associated with greater physical, cognitive, and functional decline, accessible, evidence-based dPD treatment may enhance global PD outcomes.

\section{Study funding}

This study was funded by the Michael J. Fox Foundation for Parkinson's Research and the Parkinson's Alliance (Parkinson's Unity Walk).

\section{Disclosure}

R.D. Dobkin received a research grant from the Michael J. Fox Foundation for Parkinson's Research and the Parkinson's Alliance (Parkinson's Unity Walk) to support this project. S.L. Mann, M.A. Gara, A. Interian, K.M. Rodriguez, and M. Menza report no relevant disclosures. Go to Neurology.org/ $\mathrm{N}$ for full disclosures.

\section{Publication history}

Received by Neurology August 13, 2019. Accepted in final form November 18, 2019.

\section{Appendix Authors}

\begin{tabular}{|c|c|c|}
\hline Name & Location & Contribution \\
\hline $\begin{array}{l}\text { Roseanne } \\
\text { D. Dobkin, } \\
\text { PhD }\end{array}$ & $\begin{array}{l}\text { Rutgers-Robert Wood } \\
\text { Johnson Medical School, } \\
\text { Piscataway; VA New Jersey } \\
\text { Health Care System, Lyons }\end{array}$ & $\begin{array}{l}\text { Dr. Dobkin had full access to } \\
\text { all study data and takes } \\
\text { responsibility for the } \\
\text { integrity of the data and the } \\
\text { accuracy of data analysis; } \\
\text { research project } \\
\text { conception, organization, } \\
\text { and execution; statistical } \\
\text { analysis design and } \\
\text { execution; writing of first } \\
\text { draft, review and critique }\end{array}$ \\
\hline
\end{tabular}

Appendix (continued)

\begin{tabular}{lll}
\hline Name & Location & Contribution \\
\hline $\begin{array}{ll}\text { Sarah L. } \\
\text { Mann, PhD }\end{array}$ & $\begin{array}{l}\text { VA New Jersey Health Care } \\
\text { System, Lyons }\end{array}$ & $\begin{array}{l}\text { Research project } \\
\text { conception, organization, } \\
\text { and execution; statistical } \\
\text { analysis review and critique; } \\
\end{array}$ \\
& $\begin{array}{l}\text { writing first draft, review, } \\
\text { and critique }\end{array}$
\end{tabular}

\begin{tabular}{lll}
\hline $\begin{array}{l}\text { Michael A. } \\
\text { Gara, PhD }\end{array}$ & $\begin{array}{l}\text { Rutgers-Robert Wood } \\
\text { Johnson Medical School, } \\
\text { Piscataway, NJ }\end{array}$ & $\begin{array}{l}\text { Research project } \\
\text { conception, organization, } \\
\text { and execution; statistical } \\
\text { analysis design and } \\
\text { execution; writing of first } \\
\text { draft, review, and critique }\end{array}$ \\
\hline $\begin{array}{ll}\text { Alejandro } \\
\text { Interian, }\end{array}$ & VA New Jersey Health Care & $\begin{array}{l}\text { Research project } \\
\text { PhD }\end{array}$ \\
& System, Lyons & $\begin{array}{l}\text { organization; statistical } \\
\text { analysis review and critique; } \\
\text { writing of first draft, review, } \\
\text { and critique }\end{array}$ \\
& &
\end{tabular}

\begin{tabular}{ll}
\hline Kailyn M. & Rutgers-Robert Wood \\
Rodriguez, & Johnson Medical School, \\
BA & Piscataway, NJ
\end{tabular}

Research project

organization and execution; statistical analysis review and critique; writing of first draft, review, and critique

\begin{tabular}{ll}
\hline Matthew & Rutgers-Robert Wood \\
Menza, MD & Johnson Medical School, \\
& Piscataway, NJ
\end{tabular}

Research project conception, organization, and execution; statistical analysis review and critique; manuscript review and critique

\section{References}

1. Weintraub D, Mamikonyan E. The neuropsychiatry of Parkinson disease: a perfect storm. Am J Geriatr Psychiatry 2019;27:998-1018.

2. Starkstein SE, Mayberg HS, Leiguarda R, Preziosi TJ, Robinson RG. A prospective longitudinal study of depression, cognitive decline, and physical impairments in patients with Parkinson's disease. J Neurol Neurosurg Psychiatry 1992;55:377-382.

3. Ravina B, Camicioli R, Como PG, et al. The impact of depressive symptoms in early Parkinson disease. Neurology 2007;69:342-347.

4. Straka I, Minár M, Gažová A, Valkovič P, Kyselovič J. Clinical aspects of adherence to pharmacotherapy in Parkinson disease: a PRISMA-compliant systematic review. Medicine 2018;97:e10962.

5. Balash Y, Peretz C, Leibovich G, Herman T, Hausdorff J, Giladi N. Falls in outpatients with Parkinson's disease. J Neurol 2005;252:1310-1315.

6. Qureshi SU, Amspoker AB, Calleo JS, Kunik ME, Marsh L. Anxiety disorders, physical illnesses, and health care utilization in older male veterans with Parkinson disease and comorbid depression. J Geriatr Psychiatry Neurol 2012;25:233-239.

7. McCrone P, Allcock LM, Burn DJ. Predicting the cost of Parkinson's disease. Mov Disord 2007;22:804-812.

8. Forsaa EB, Larsen JP, Wentzel-Larsen T, Herlofson K, Alves G. Predictors and course of health-related quality of life in Parkinson's disease. Mov Disord 2008;23: 1420-1427.

9. Balestrino R, Martinez-Martin P. Reprint of "Neuropsychiatric symptoms, behavioural disorders, and quality of life in Parkinson's disease." J Neurol Sci 2017;374:3-8.

10. Pontone GM, Bakker CC, Chen S, et al. The longitudinal impact of depression on disability in Parkinson disease. Int J Geriatr Psychiatry 2016;31:458-465.

11. Landau S, Harris V, Burn D, et al. Anxiety and anxious-depression in Parkinson's disease over a 4-year period: a latent transition analysis. Psychol Med 2016;46: 657-667.

12. Lachner C, Armstrong MJ, Gruber-Baldini AL, et al. Discordance between physician assessment and patient-reported depressive symptoms in Parkinson disease. J Geriatr Psychiatry Neurol 2017;30:191-195.

13. Seppi K, Ray Chaudhuri K, Coelho M, et al. Update on treatments for nonmotor symptoms of Parkinson's disease: an evidence-based medicine review. Mov Disord 2019;34:180-198.

14. Hinnell C, Hurt CS, Landau S, Brown RG, Samuel M, Group PPS. Nonmotor versus motor symptoms: how much do they matter to health status in Parkinson's disease? Mov Disord 2012;27:236-241.

15. Beck AT. Cognitive Therapy of Depression. New York: Guilford Press; 1979.

16. Swalwell C, Pachana NA, Dissanayaka NN. Remote delivery of psychological interventions for Parkinson's disease. Int psychogeriatrics 2018;30:1783-1795. 
17. Koychev I, Okai D. Cognitive-behavioural therapy for non-motor symptoms of Parkinson's disease: a clinical review. Evidence-Based Ment Health 2017;20:15-20.

18. Dobkin RD, Menza M, Allen LA, et al. Cognitive-behavioral therapy for depression in Parkinson's disease: a randomized, controlled trial. Am J Psychiatry 2011;168: 1066-1074.

19. Oehlberg K, Barg FK, Brown GK, Taraborelli D, Stern MB, Weintraub D. Attitudes regarding the etiology and treatment of depression in Parkinson's disease: a qualitative study. J Geriatr Psychiatry Neurol 2008;21:123-132.

20. Dobkin RD, Rubino JT, Friedman J, Allen LA, Gara MA, Menza M. Barriers to mental health care utilization in Parkinson's disease. J Geriatr Psychiatry Neurol 2013;26: $105-116$.

21. Dorsey ER, Glidden AM, Holloway MR, Birbeck GL, Schwamm LH. Teleneurology and mobile technologies: the future of neurological care. Nat Rev Neurol 2018;14:285.

22. Titova N, Chaudhuri KR. Personalized medicine in Parkinson's disease: time to be precise. Mov Disord 2017;32:1147.

23. Gelb DJ, Oliver E, Gilman S. Diagnostic criteria for Parkinson disease. Arch Neurol 1999;56:33-39.

24. American Psychiatric Association. Diagnostic and Statistical Manual of Mental Disorders (DSM-5). Washington: American Psychiatric Press; 2013.

25. First MB, Spitzer RL, Gibbon M, Williams JB. User's Guide for the Structured Clinical Interview for DSM-IV axis I Disorders SCID-I: Clinician Version. Washington: American Psychiatric Press; 1997.

26. Marsh L, McDonald WM, Cummings J, Ravina B. Provisional diagnostic criteria for depression in Parkinson's disease: report of an NINDS/NIMH Work Group. Mov Disord 2006;21:148-158.

27. Dalrymple-Alford J, MacAskill M, Nakas C, et al. The MoCA well-suited screen for cognitive impairment in Parkinson disease. Neurology 2010;75:1717-1725.

28. Hamilton M. Hamilton Depression Scale. In: Guy W, ed. ECDEU Assessment Manual for Psychopharmacology, Revised Edition. Rockville: National Institute of Mental Health; 1976: 179-192.

29. Frank E, Prien RF, Jarrett RB, et al. Conceptualization and rationale for consensus definitions of terms in major depressive disorder: remission, recovery, relapse, and recurrence. Arch Gen Psychiatry 1991;48:851-855.

30. Hamilton M. The assessment of anxiety status by rating. Br J Med Psychol 1959;32: $50-55$.

31. Ware JE Jr, Sherbourne CD. The MOS 36-item short-form health survey (SF-36): I: conceptual framework and item selection. Med Care 1992;30:473-483.

32. Fereshtehnejad S-M. Strategies to maintain quality of life among people with Parkinson's disease: what works? Neurodegenerative Dis Manag 2016;6:399-415.

33. Alloy LB, Abramson LY, Hogan ME, et al. The Temple-Wisconsin Cognitive Vulnerability to Depression Project: lifetime history of axis I psychopathology in individuals at high and low cognitive risk for depression. J Abnorm Psychol 2000; 109:403.
34. Bodenheimer T, Lorig K, Holman H, Grumbach K. Patient self-management of chronic disease in primary care. JAMA 2002;288:2469-2475.

35. Hayes AF. Introduction to Mediation, Moderation, and Conditional Process Analysis: A Regression-Based Approach. New York: Guilford Publications; 2017.

36. Freedland KE, Mohr DC, Davidson KW, Schwartz JE. Usual and unusual care: existing practice control groups in randomized controlled trials of behavioral interventions. Psychosomatic Med 2011;73:323-335.

37. Fernie BA, Kollmann J, Brown RG. Cognitive behavioural interventions for depression in chronic neurological conditions: a systematic review. J Psychosomatic Res 2015;78:411-419.

38. Gould RL, Coulson MC, Howard RJ. Cognitive behavioral therapy for depression in older people: a meta-analysis and meta-regression of randomized controlled trials. J Am Geriatr Soc 2012;60:1817-1830.

39. Wiles N, Thomas L, Abel A, et al. Cognitive behavioural therapy as an adjunct to pharmacotherapy for primary care based patients with treatment resistant depression results of the CoBalT randomised controlled trial. Lancet 2013;381:375-384.

40. Kornstein SG, Schneider RK. Clinical features of treatment-resistant depression. J Clin Psychiatry 2001;62:18-25.

41. Schulman-Green D, Jaser SS, Park C, Whittemore R. A metasynthesis of factors affecting self-management of chronic illness. J Adv Nurs 2016;72:1469-1489.

42. Julien CL, Rimes KA, Brown RG. Rumination and behavioural factors in Parkinson's disease depression. J Psychosom Res 2016;82:48-53.

43. Dimidjian S, Barrera M Jr, Martell C, Munoz RF, Lewinsohn PM. The origins and current status of behavioral activation treatments for depression. Annu Rev Clin Psychol 2011;7:1-38.

44. Bucks R, Cruise K, Skinner T, Loftus A, Barker R, Thomas M. Coping processes and health-related quality of life in Parkinson's disease. Int J Geriatr Psychiatry 2011;26: 247-255.

45. Cuijpers P, Reijnders M, Huibers MJ. The role of common factors in psychotherapy outcomes. Annu Rev Clin Psychol 2018;15:207-231.

46. Moore KA, Seeney F. Biopsychosocial predictors of depressive mood in people with Parkinson's disease. Behav Med 2007;33:29-38.

47. Dobkin RD, Mann SL, Interian A, Gara MA, Menza M. Cognitive behavioral therapy improves diverse profiles of depressive symptoms in Parkinson's disease. Int J Geriatr Psychiatry 2019;34:722-729.

48. Dobkin RD, Rubino JT, Allen LA, et al. Predictors of treatment response to cognitivebehavioral therapy for depression in Parkinson's disease. J Consult Clin Psychol 2012;80 694.

49. American Telemedicine Association. 2019 State of the States: Coverage and Reimbursement. Washington: American Telemedicine Association; 2019.

50. The Michael J. Fox Foundation for Parkinson's Research. Our Public Policy Priorities. New York: The Michael J. Fox Foundation for Parkinson's Research. Accessed August $1,2019$. 


\section{Neurology}

\section{Telephone-based cognitive behavioral therapy for depression in Parkinson disease: A randomized controlled trial}

Roseanne D. Dobkin, Sarah L. Mann, Michael A. Gara, et al.

Neurology 2020;94;e1764-e1773 Published Online before print April 1, 2020

DOI 10.1212/WNL.0000000000009292

This information is current as of April 1, 2020

\section{Updated Information \& Services}

References

Citations

Subspecialty Collections

Permissions \& Licensing

Reprints including high resolution figures, can be found at: http://n.neurology.org/content/94/16/e1764.full

This article cites 43 articles, 4 of which you can access for free at: http://n.neurology.org/content/94/16/e1764.full\#ref-list-1

This article has been cited by 4 HighWire-hosted articles: http://n.neurology.org/content/94/16/e1764.full\#\#otherarticles

This article, along with others on similar topics, appears in the following collection(s):

Class I

http://n.neurology.org/cgi/collection/class_1

Clinical trials Randomized controlled (CONSORT agreement)

http://n.neurology.org/cgi/collection/clinical_trials_randomized_contro

lled_consort_agreement

Depression

http://n.neurology.org/cgi/collection/depression

Parkinson's disease/Parkinsonism

http://n.neurology.org/cgi/collection/parkinsons_disease_parkinsonism Quality of life

http://n.neurology.org/cgi/collection/quality_of_life

Information about reproducing this article in parts (figures,tables) or in its entirety can be found online at:

http://www.neurology.org/about/about_the_journal\#permissions

Information about ordering reprints can be found online:

http://n.neurology.org/subscribers/advertise

Neurology ${ }^{\circledR}$ is the official journal of the American Academy of Neurology. Published continuously since 1951, it is now a weekly with 48 issues per year. Copyright Copyright $@ 2020$ The Author(s). Published by Wolters Kluwer Health, Inc. on behalf of the American Academy of Neurology.. All rights reserved. Print ISSN: 0028-3878. Online ISSN: 1526-632X.

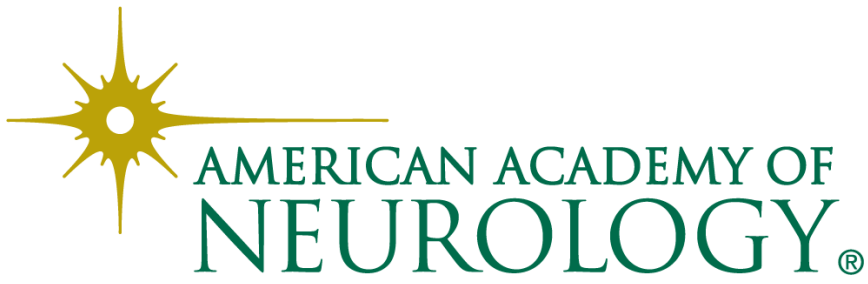

